\title{
Suitability of and tolerance to Iotrolan 300 in bronchography via the fibreoptic bronchoscope
}

\author{
S K Morcos, P B Anderson, S V Baudouin, C Clout, N Fairlie, C Baudouin, N Warnock
}

\begin{abstract}
The contrast agent Iotrolan 300 has potential advantages for bronchography over previous agents in that it can be injected directly through the bronchoscope and it does not obscure bronchoscopic vision or interfere with further bronchoscopic procedures. It was used for selective bronchography in 20 patients with suspected bronchiectasis. Side effects and change in $F E V_{1}$ and in arterial oxygen saturation were compared in these patients and in 14 patients undergoing bronchoscopy for suspected carcinoma. Thirteen of the 20 patients undergoing bronchography had side effects, mainly headache, nausea, and a feeling of heat or flushing. The fall in FEV $_{1}$ at four hours $(0.31)$ did not differ from the fall in the control group (0.1 1$)$. The fall in arterial oxygen saturation $\left(\mathrm{SaO}_{2}\right)$ during bronchography $(9.4 \%)$ did not differ significantly from the fall during bronchoscopy in the control group (6.1\%). Iotrolan gave good quality bronchograms, which in all cases provided a diagnosis. Iotrolan appears to be suitable for bronchography by fibreoptic bronchoscope and to be well tolerated.
\end{abstract}

Bronchography via the fibreoptic bronchoscope has important diagnostic potential. ${ }^{1}$ The usual contrast agent used, Dionosil (Glaxo Laboratories, Greenford, Middlesex), has several disadvantages. It is difficult to administer, obscures bronchoscopic vision, and has been shown to compromise lung function. ${ }^{2}$ We report our experience with Iotrolan 300 (Schering AG, Berlin), which, unlike Dionosil, can be injected directly through the bronchoscope's suction channel. ${ }^{3}$

Diagnostic Radiology

$S \mathrm{~K}$ Morcos

C Clout

N Fairlie

C Baudouin

N Warnock

Department of

Thoracic Medicine,

Lodge Moor Hospital,

Sheffield

P B Anderson

$S$ V Baudouin

Address for reprint requests Dr S K Morcos, X-ray Department Lodge Moor Hospital Sheffield S10 4IH.

Accepted 3 April 1990

\section{Methods}

Selective bronchography was performed in 14 women and six men with suspected bronchiectasis (mean age 46.2 (range 35-64) years). Ten men and four women (mean age 54.5 (range 27-68) years) having a bronchoscopy for suspected carcinoma acted as control subjects.

Bronchoscopy was performed under local anaesthesia after morphine and atropine premedication. Bronchography was performed during bronchoscopy, Iotrolan 300 being injected via the suction channel. Spirometry was determined before and four hours after bronchoscopy (Pocket Spirometer, Micro Medical Instruments, Rochester, Kent). Arterial oxygen saturation $\left(\mathrm{SaO}_{2}\right)$ was monitored (Ohmeda Biox 3700E, USA) for four hours from the start of the procedure.

Bronchography was bilateral in 14 patients. Altogether 182 segments were examined (mean 9, range 4-16 per patient), 15.4 (range 6-28) $\mathrm{ml}$ of Iotrolan being used.

\section{Results}

Thirteen patients ( 12 of them women) undergoing bronchography had side effects that included headache (five), nausea or vomiting (six), and a feeling of heat or flushing (five). Coughing occurred in three patients after the administration of Iotrolan. Three control subjects (two of them men) developed minor reactions. The bronchographic examination was generally acceptable to the patients, easy to perform, and not time consuming (mean (SD) $15 \cdot 2(7 \cdot 2) \mathrm{min}$ ).

Baseline spirometry and the changes over the four hours were similar in the two groups (table). The mean (SD) maximum fall in $\mathrm{SaO}_{2}$ (baseline - nadir) was $9.4 \%(4.2 \%)$ in the bronchography and $6 \cdot 1 \%(3.4 \%)$ in the control group. $\mathrm{SaO}_{2}$ fell below $90 \%$ transiently on introduction of Iotrolan in six patients but oxygen administration was not necessary. The quality of the bronchogram was rated as good in 13 patients and excellent in the remaining seven. All bronchograms allowed a diagnosis to be made or excluded (figure)-bronchiectasis in 14 cases and chronic bronchitis in

!Effect of bronchography and bronchoscopy on spirometric values and arterial oxygen saturation $\left(\mathrm{SaO}_{2}\right)$ (means with standard deviations in parentheses.

\begin{tabular}{lllll}
$\begin{array}{l}\text { Forced vital capacity }(1): \\
\text { Baseline }\end{array}$ & 3.25 & $(0.9)$ & 3.16 & $(1 \cdot 12)$ \\
4 hours & 2.80 & $(0.9)$ & 2.97 & $(0.75)$ \\
& & & & \\
$\mathrm{SaO}_{2}(\%):$ & & & & \\
$\quad$ Baseline & 94.8 & $(3.13)$ & 93.6 & $(2.99)$ \\
End of procedure & 90.7 & $(4.92)$ & 93 & $(4.86)$ \\
4 hours & 92.5 & $(2 \cdot 24)$ & 92.9 & $(3.37)$ \\
\hline
\end{tabular}




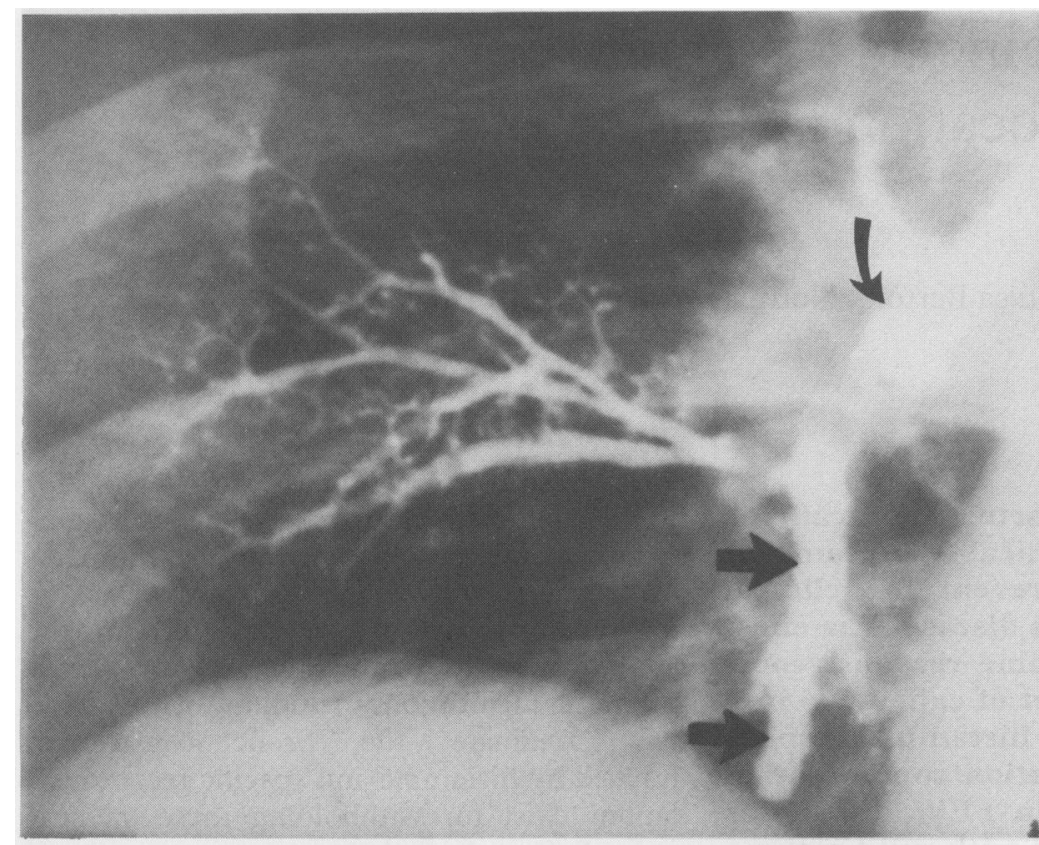

Selective bronchogram of the basal segments of the right lower lobe showing tubular bronchiectasis of the posterior segment (straight arrows) and a normal bronchial tree in the lateral segment with filling of the small distal air passages in contrast to the bronchiectatic segment. The tip of the bronchoscope (curved arrow) lies in the right lower lobe bronchus. four, the bronchial tree being normal in two cases.

\section{Discussion}

Intrabronchial Iotrolan 300 did not cause serious side effects. No inflammatory response was seen histologically in a lobe removed five days after bronchography. Saturation and spirometric changes were less than those reported with Dionosil ${ }^{2}$ and no greater than those caused by bronchoscopy alone in the control group. Diagnostic bronchograms were obtained in all cases. A dose of 2-3 ml Iotrolan 300 per lung segment is suggested, with a maximum of $25 \mathrm{ml}$ per patient.

Iotrolan 300 appears to be suitable for bronchography and to be well tolerated. The value of the technique is currently being evaluated.

1 Flower CDR, Shneerson JM. Bronchography via the fibreoptic bronchoscope. Thorax 1984;35:260-3.

2 Goldman JM, Currie DC, Morgan AD, Collins JV. Arterial oxygen saturation during bronchography via the fibreoxygen saturation during bronchography
optic bronchoscope. Thorax 1987;42:634-5.

3 Morcos SK, Baudouin SV, Anderson PB, Beedie R, Bury RW. Iotrolan in selective bronchography via the fibreoptic bronchoscope. Br J Radiol 1989;62:383-5. 